This document is the Accepted Manuscript version of a Published Work that appeared in final form in Analytical Chemistry 2016, 88 (12), pp 6395-6402 DOI: 10.1021/acs.analchem.6b00864, copyright (C) 2016 American Chemical Society after peer review and technical editing by the publisher. To access the final edited and published work see [insert ACS Articles on Request author-directed link to Published Work, see https://pubs.acs.org/doi/abs/10.1021/acs.analchem.6b00864.

\title{
Multi-spectroscopic and isotopic ratio analysis to characterize the in- organic binder used on Pompeian pink and purple lake pigments
}

\author{
Iker Marcaida, ${ }^{\S}$ Maite Maguregui, ${ }^{\xi, *}$ Héctor Morillas, ${ }^{\S}$ Cristina García-Florentino, ${ }^{\S}$ Ulla Knuutinen, ${ }^{\psi,}{ }^{\ddagger}$ \\ Jose Antonio Carrero, ${ }^{\S}$ Silvia Fdez-Ortiz de Vallejuelo, ${ }^{\S}$ Africa Pitarch, ${ }^{\ddagger} \pi$ Juan Manuel Madariaga ${ }^{\S}$ \\ $\S$ Department of Analytical Chemistry, Faculty of Science and Technology, University of the Basque Country UPV/EHU, \\ P.O. Box 644, 48080 Bilbao, Basque Country, Spain \\ $\xi_{\text {}}$ Department of Analytical Chemistry, Faculty of Pharmacy, University of the Basque Country UPV/EHU, P.O. Box 450, \\ 01080 Vitoria-Gasteiz, Basque Country, Spain \\ ${ }^{\psi}$ University of Helsinki, Faculty of Science, Department of Chemistry, P.O. Box 44, FI-00014, Finland. \\ ${ }^{\ddagger}$ Jyväskylä University, Faculty of Humanities, Department of Art and Culture Studies/ Museology, P. O. Box 35, FIN-40014, \\ Finland \\ ${ }^{¥}$ UMR-CNRS 5199 PACEA, Préhistoire, Paléoenvironnement, Patrimoine, Université de Bordeaux, Bâtiment B18, Allée \\ Geoffroy St Hilaire, 33615 Pessac, France \\ ${ }^{\pi}$ Grup de Recerca Aplicada al Patrimoni Cultural (GRAPAC), Departament de Biologia Animal, de Biologia Vegetal i \\ d'Ecologia, Facultat de Biociènces, Univeritat Autònoma de Barcelona, Campus Bellaterra, 08193 Bellaterra, Spain
}

\begin{abstract}
Due to the fact that pigments are not ubiquitous in the archaeological record, the application of non-invasive analytical methods is a necessity. In this work, pink and purple lake pigments recovered from the excavations of the ancient city of Pompeii (Campania, Italy) and preserved in their original bowls at the Naples National Archaeological Museum (Italy) were analyzed to characterize the composition of their inorganic binders (mordants). In-situ preliminary analyses using a handheld Energy Dispersive $\mathrm{X}$-ray Fluorescence spectrometer (HH-ED-XRF) allowed us to determine the use of an aluminosilicate enriched in $\mathrm{Cu}$ and $\mathrm{Pb}$. Scanning Electron Microscopy coupled to Energy Dispersive X-ray Spectrometry (SEM-EDS) and benchtop ED-XRF analyses confirmed these results, while Inductively Coupled Plasma Mass Spectrometry (ICP-MS) allowed to determine the concentration of major, minor and trace elements. The use of other techniques such as X-ray Diffraction (XRD), and micro-Raman and infrared spectroscopies allowed to characterize the pigments at molecular level. The high concentration of $\mathrm{Cu}$ detected in the pigments (1228-12937 $\left.\mu \mathrm{g} \cdot \mathrm{g}^{-1}\right)$ could be related to the addition of $\mathrm{Cu}$ salts to obtain the desired final hue. The concentrations of $\mathrm{Pb}(987-2083$ $\left.\mu \mathrm{g} \cdot \mathrm{g}^{-1}\right)$ was also remarkable. Lead isotopic ratio analysis $\left({ }^{206} \mathrm{~Pb} /{ }^{207} \mathrm{~Pb}\right)$ suggested a possible origin related to the leaching of the ancient lead pipes from Pompeii and the subsequent transfer to the buried pigments or to the inorganic binder. Molecular analysis also showed that the binder is composed of an allophane-like clay. Moreover, it was possible to determine that to obtain the final purple hue of a specific pigment, Pompeian blue pigment was also mixed to the dyed clay.
\end{abstract}

\section{INTRODUCTION}

One of the key questions in the study of ancient pigments is the identification of paint recipes, which may give useful information about the material knowledge of a culture and helps in the identification of trading routes. ${ }^{1,2}$ The use of pigments to give color to artworks, textiles or cosmetics is well known since the prehistory. Pigments are inorganic or organic dry color powders, while lake pigments are made by precipitating an organic dye upon an usually insoluble mordant or binder, which is an inorganic material such as a silicate or an aluminate. ${ }^{3}$ In ancient times chalk, white clays and crushed bones were used as mordants. ${ }^{3}$ In the last case, for the manufacture of the lake pigments, Roman people used to take the clays directly from the ground and to dye them with an organic colorant (e.g. madder lake, Tyrian Purple, etc) ${ }^{4}$ to obtain the desired color. Most of the lake pigments manufactured during the Roman period were colored on red, pink and purple shades. These lake pigments were used in wall paintings, textiles, ${ }^{5}$ cosmetics, codices, ${ }^{6}$ and ceramics, ${ }^{7}$ among others.

The archaeological site of Pompeii is one of the most impressive remains of the Roman period. In the literature, many are the works dealing with the study of inorganic pigments used in the ancient wall paintings from this archaeological site. ${ }^{8-11}$ Nevertheless, few works can be found about the characterization of pink or purple lake pigments used in its ancient paintings. ${ }^{7,12,13}$ Considering its high historical and artistic value, and due to the fact that this kind of pigments are extremely rare, the application of non-invasive analytical methods is a necessity. Therefore, the best strategy would be the application of portable/handheld instrumentation, to obtain results in-situ (in the museum or in a storage room, for exam- 
ple) ${ }^{14,15}$ without the necessity of taking any sample. Nowadays, with the technological development, the size and weight of portable/handheld instruments has been reduced considerably, and a wide variety of mobile instruments can be found in the market. Despite the fact that the sensitivity and resolution of this new generation of portable instruments has been improved, in some cases, it is necessary to take or extract a (micro) sample to confirm and/or extend the results obtained insitu. Regarding the portable instruments, the best option is to select analytical techniques that do not affect the integrity of the materials under study. In this sense, different spectroscopic techniques can be mentioned. For the elemental analysis, handheld/portable energy dispersive X-ray spectrometers (HH-ED-XRF) and portable laser induced breakdown spectrometers (LIBS) are the most used ones. ${ }^{16-19}$ For the molecular characterization, portable Raman, infrared, X-ray diffraction (XRD) and UV-Visible-NIR spectrometers are good options to determine the mineralogical composition of the pigments under study. ${ }^{17-19}$

In this work an analytical methodology based on the combined use of elemental and molecular non-invasive techniques was applied to perform an unequivocal characterization of the composition of the inorganic binder or mordant used to manufacture Pompeian pink and purple lake pigments. For the elemental characterization, an in-situ preliminary screening of the pigments was conducted using a HH-ED-XRF. Further analyses in the laboratory were carried out using a benchtop EDXRF spectrometer and a Scanning Electron Microscope coupled to an Energy Dispersive X-ray Fluorescence spectrometer (SEM-EDS). In order to determine the concentration of major, minor and trace elements of these lake pigments, Inductively Coupled Plasma Mass Spectrometry analysis (ICP-MS) preceded by an acid extraction of the raw lake pigments was carried out. The molecular characterization was done using XRD, Raman, and infrared spectroscopies (in FTIR and ATR modes). Apart from the quantification of the elements present in the inorganic matrix of the lake pigments, lead isotopic ratio analysis was also performed.

\section{EXPERIMENTAL SECTION}

Samples. Two pink lake pigments (ref. numbers 117323 and 117342) and one purple lake pigment (ref. number 117365 ) from the "Museo Archeologico Nazionale di Napoli", MANN (National Archeological Museum, Naples, Italy) were considered in this work. These lake pigments were recovered from the archaeological excavation of Pompeii and stored in their original bowls at the museum (see Figure S-1).

In-Situ Analytical Campaign. Before the sampling of the archaeological lake pigments, we were allowed to perform a quick elemental in-situ screening analysis of the two pink lake pigments in the MANN using a HH-ED-XRF spectrometer. For that purpose, an Innov-X Alpha Series (Innov-X Systems Inc., woburn, MA, USA) HH-ED-XRF spectrometer, which employs a miniature, low power Ag X-ray tube as a source for sample excitation was used. The description of the instrument and the conditions used for the spectral acquisitions are described elsewhere. ${ }^{20}$ The analyses were performed directly introducing the sampling interface in the original bowls containing the lake pigments. Ten repetitive measurements were performed in order to obtain representative results. To prevent the contamination of the sampling interface, a Mylar film was placed on the top of the lake pigments surface.

Although this instrument is only capable to register the spectra for the elements with an atomic number higher than 18 (heavy elements), it is able to determine the presence of elements with a lower atomic number (light elements) by giving their corresponding semi-quantitative values on the basis of Fundamental Parameter methods. It should be noted that elemental quantification in these kinds of samples is not straightforward, and the quantification data given by the instrument should be handled with care, because the sampling volume is not precisely determined. Additionally, matrix effects can hamper the quantification procedure. Therefore, in this work, the semi-quantitative values from the light and heavy elements were not considered. Instead, the net areas of K-alpha lines of each detected element in the spectrum normalized against the $\mathrm{K}$-alpha line of the element composing the tube (Ag in this case) were used. Considering the interference of $\mathrm{As}$ and $\mathrm{Pb}$ at $10.5 \mathrm{keV}$ (K-alpha of As and L-alpha of $\mathrm{Pb}$ ), for these elements the areas of K-beta and L-beta lines respectively were normalized.

Sampling After In-Situ Measurements. The sampling procedure was carried out taking small quantities of powder from the upper, middle and lower parts of each bowl when the lake pigment was in powder form (samples 117342 and 117365), and taking three small pigment fragments in the case of sample 117323. All the samples were preserved in glass containers until their analysis.

Analytical Methodology in the Laboratory. For the elemental analysis of the lake pigments in the laboratory, the M4 Tornado (Bruker Nano GmbH, Berlin, Germany) ED-XRF was used. Ten repetitive punctual measurements of each lake pigments were performed with a lateral resolution of $1 \mathrm{~mm}$ in order to obtain XRF spectra that represent the elemental composition of the whole sample. In this instrument the X-ray $\mathrm{Rh}$ anode tube operates at up to $50 \mathrm{kV}$ with a maximum current of $700 \mu \mathrm{A}$, which were the conditions considered for the spectra acquisition. The live time used for each punctual measurement was 300 seconds. Although the software implements the MQuant quantification software package based on the use of Fundamental Parameters quantification methods, as in the $\mathrm{HH}$ ED-XRF measurements, instead of using the semi-quantitative information given by the software, the net counts of K-alpha lines of each detected element in the spectrum normalized against the net counts of $\mathrm{K}$-alpha line of the $\mathrm{Rh}$ from the tube were used to extract conclusions. The possible interferences on the K-alpha line of each element were removed thanks to a previous deconvolution process of the XRF lines. Additional information related with the instrument can be checked elsewhere. $^{21}$

In order to improve the detection of the elements with an atomic number lower than 13, SEM-EDS analyses were also performed using a X-Max energy dispersive X-ray spectrometer (Oxford Instruments, Abingdon, Oxfordshire, UK) coupled to an $\mathrm{EVO}^{\mathbb{R}} 40$ Scanning Electron Microscope (Carl Zeiss NTS $\mathrm{GmbH}$, Germany). The elemental analysis was carried out using $8.5 \mathrm{~mm}$ working distance, a $35^{\circ}$ take-off angle and an acceleration voltage of $30 \mathrm{kV}$. An integration time of $50 \mathrm{~s}$ was employed to improve the signal-to-noise ratio of EDS spectra. 
The spectral data treatment was carried out using the INCA software (Oxford Instruments, Abingdon, Oxfordshire, UK). Although this software is able to offer a semi-quantitative approach of the elements present in the sample under study, once more, we decided to take into account the K-alpha net areas of each detected element.

For the quantification of elements present in the lake pigments, ICP-MS was used. Prior to this analysis, the samples were dried until constant weight using an oven and lately manually homogenized using an agate mortar in order to ensure the representativeness of the quantitative results. After that, an acid extraction of the three pigments was conducted. Considering the few amount of sample available an isolated extraction of each lake pigment was carried out using $10 \mathrm{mil}-$ ligrams. Each pigment mass was mixed with $10 \mathrm{~mL}$ of $10 \%$ $\mathrm{HCl}$ and the mixture was heated up to $60^{\circ} \mathrm{C}$ under continuous stirring. The resultant acid extracts were analyzed by ICP-MS (NexION 300, Perkin Elmer, Massachusetts, USA). Additional information related with the technique and analytical methodology can be reviewed elsewhere. ${ }^{21}$ In the isotopic analysis, dead time and mass discrimination corrections had to be performed in order to obtain accurate lead isotope ratios. The procedure and equations to be applied can be found elsewhere. ${ }^{22}$ Linear model was used for the calculation of the mass bias factor using ${ }^{203} \mathrm{Tl}^{205} \mathrm{Tl}$ ratio from a $10 \mathrm{ng} \mathrm{g}^{-1} \mathrm{Tl}$ solution continuously added and mixed with the sample via a $\mathrm{T}$ piece. ICP-MS experimental conditions are shown in Table S-1 and $\mathrm{S}-2$.

For the molecular characterization of the lake pigments XRD, Raman and infrared spectroscopies were used. The XRD analyses were performed using a PANalytical Xpert PRO powder diffractometer equipped with a copper tube $\left(\lambda \mathrm{Cu}_{\mathrm{K} \alpha \text { media }}=1.5418 \AA, \lambda \mathrm{Cu}_{\mathrm{K} \alpha 1}=1.54060 \AA, \lambda \mathrm{Cu}_{\mathrm{K} \alpha 2}=1.54439\right.$ $\AA$ ), a vertical goniometer (Bragg-Brentano geometry), a programmable divergence aperture, an automatic interchange of samples, a secondary graphite monochromator, and a PixCel detector. Additional information related with the instrument, measurement conditions and spectral assignation can be reviewed elsewhere. ${ }^{23}$

For the micro-Raman analyses, the inVia Renishaw confocal Raman microspectrometer (Renishaw, Gloucestershire, UK) coupled to a DMLM Leica microscope with $5 \times, 20 \times$, $50 \times$, and $100 \times$ long working distance lenses was used. For the analysis of the pink and purple lake pigments, two excitation lasers, 785 (nominal laser power $350 \mathrm{~mW}$ ) and $514 \mathrm{~nm}$ (nominal laser power $350 \mathrm{~mW}$ and $50 \mathrm{~mW}$ ), were used. The spectrometer was daily calibrated by using the $520 \mathrm{~cm}^{-1}$ Raman band of a silicon chip. Lasers were set at low power (not more than $1 \mathrm{~mW}$ at the sample) in order to avoid sample decomposition. Data acquisition was carried out using the Wire 3.2 software package (Renishaw). Spectra were acquired between 100 and $3200 \mathrm{~cm}^{-1}$ during 5-15 $\mathrm{s}$ and several scans (between 1-5) were accumulated for each spectrum in order to improve the signal-to-noise ratio.

The Infrared spectra of the lake pigment were acquired through a Jasco 6300 FTIR spectrophotometer. The equipment has a Michelson interferometer at a maximum resolution of $0.07 \mathrm{~cm}^{-1}$ and a $\mathrm{Ge} / \mathrm{KBr}$ beam splitter with a DLATGS detector with Peltier temperature control. The IR measurements were performed in FTIR and in ATR mode. To acquire the spectra in FTIR mode, a pellet was prepared from each lake pigment using $\mathrm{KBr}$. For FTIR measurements 32 scans per spectrum were accumulated at a resolution of $4 \mathrm{~cm}^{-1}$ in the mid-infrared spectral range $\left(4000-400 \mathrm{~cm}^{-1}\right)$. The ATR spectra were collected directly pressing each lake pigment on a $\mathrm{ZnSe}$ crystal from a MIRacle ${ }^{\mathrm{TM}}$ Single Reflection ATR unit (PIKE Technologies, Fichburg, USA). The spectra were also collected in the mid-infrared region $\left(4000-750 \mathrm{~cm}^{-1}\right)$ recording 32 scans per spectrum at a spectral resolution of $4 \mathrm{~cm}^{-1}$.

The obtained Raman and infrared spectra were treated using the Omnic V.7.2 (Nicolet) software. The spectral interpretation was performed by comparison with spectra of pure standards registered in e-VISNICH ${ }^{24}$, e-VISARCH and e-VISART databases, ${ }^{25}$ as well as using Raman spectra contained in the en line free access RRUFF database. ${ }^{26}$

\section{RESULTS AND DISCUSSION}

In-Situ HH-ED-XRF analyses. In-situ measurements of samples 117323 and 117342 showed almost the same spectral information. In Figure 1 a representative spectrum obtained from the two Pompeian pink lake pigments can be observed.

In both pink lake pigments the same elements were identified (see Figure 1). However, in the pink lake pigment 117323 $\mathrm{Zn}$ was detected. In order to determine other possible slight differences between both pigments, the spectral information was carefully evaluated. The normalized areas of all the detected elements on each pink lake pigment are displayed in Table S-3 (see Supporting Information). Taking into consideration these data together with the related standard deviation, the normalized areas values of $\mathrm{K}, \mathrm{Ca}, \mathrm{Mn}, \mathrm{Fe}, \mathrm{Ni}, \mathrm{As}, \mathrm{Pb}, \mathrm{Sr}$ and $\mathrm{Rb}$ are quite similar in both samples. On the contrary, the normalized areas for $\mathrm{Cu}$ are significantly higher in the pink lake pigment 117342 than in the 117323 one, suggesting a considerably high concentration of both elements in this Pompeian lake pigment. This observation will be confirmed by further non-invasive (qualitative) and destructive (quantitative) analyses in the laboratory.

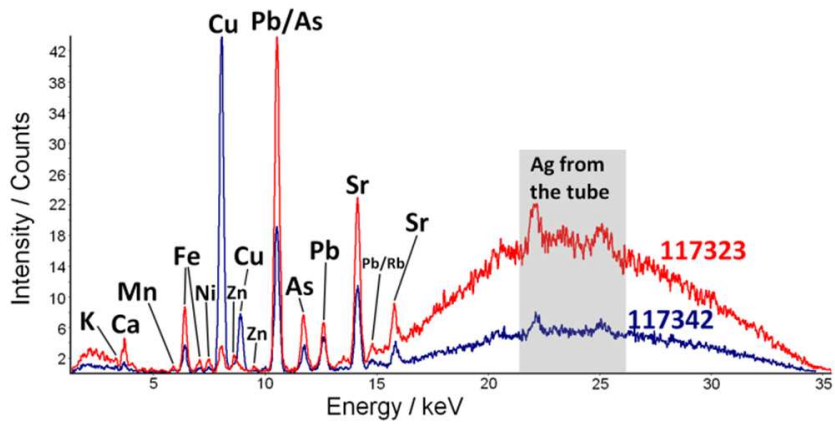

Figure 1. XRF spectra of Pompeian pink lake pigments 117323 (in red) and 117342 (in blue) obtained by using the HH-ED-XRF spectrometer at the MANN.

Microscopic observations of the lake pigments. Prior to the elemental and molecular analysis of the lake pigments, microscopic observations were conducted in order to observe their main features. In Figure 2, different microphotographs of the studied pigments can be observed. The microscopic appearance of the two pink lake pigments is very similar. On the contrary, the purple lake pigment 117365 is made up of a mixture of pink and blue pigment grains (see Figure 2 G-I). Therefore, a selective measurement of the two types of pig- 
ment should be performed in order to determine their nature separately.

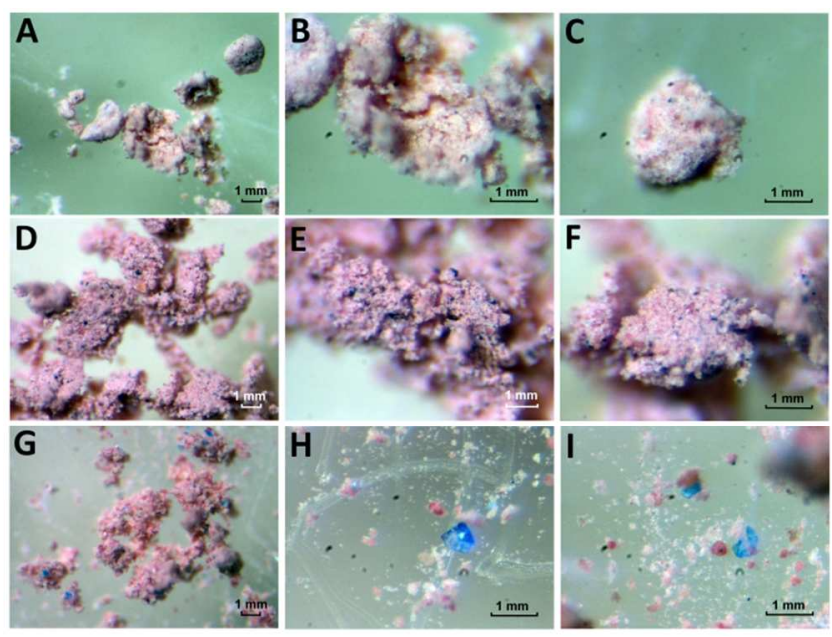

Figure 2. Microphotographs of the Pompeian pink lake pigment 117323 (A-C), 117342 (D-F) and the purple lake pigment 117365 (G-I).

Laboratory non-invasive X-ray-based analytical techniques for the elemental characterization of the samples. In order to confirm the in-situ elemental results, additional laboratory ED-XRF analyses were performed. The obtained results are shown in Table 1. Mn and Sr normalized net counts are quite similar for both pink lake pigments, while $\mathrm{Ca}, \mathrm{Fe}, \mathrm{Ni}$ and As normalized net counts are higher in sample 117323. Comparing the normalized net counts of all the elements in the lake pigments, the highest values belong to the pink lake pigment 117323 , except for $\mathrm{Fe}, \mathrm{Pb}$ and $\mathrm{Cu}$. Fe value is higher in the purple lake pigment $117365, \mathrm{~Pb}$ values are considerably higher in the pink lake pigment 117342 , and $\mathrm{Cu}$ values are higher in the other two samples. The highest normalized net counts value for $\mathrm{Cu}$ is recorded in the purple lake pigment 117365 , what suggests that the blue pigment grains composing the purple lake pigment could be related with the use of Pompeian blue (a tretrasilicate of calcium and copper $-\mathrm{CaCuSi}_{4} \mathrm{O}_{10^{-}}$ also known as cuprorivaite). These observations are consistent with the results obtained through the in-situ ED-XRF measurements.

Table 1. Normalized net counts for each element detected in the Pompeian pink (117323 and 117342) and purple (117365) lake pigments using the benchtop ED-XRF spectrometer.

\begin{tabular}{|c|c|c|c|}
\hline Elements & $\mathbf{1 1 7 3 2 3}$ & $\mathbf{1 1 7 3 4 2}$ & $\mathbf{1 1 7 3 6 5}$ \\
\hline $\mathbf{A l}$ & $0.13 \pm 0.01$ & $0.162 \pm 0.003$ & $0.106 \pm 0.002$ \\
\hline $\mathbf{S i}$ & $0.17 \pm 0.01$ & $0.21 \pm 0.01$ & $0.31 \pm 0.01$ \\
\hline $\mathbf{P}$ & $0.0031 \pm 0.0004$ & $0.05 \pm 0.07$ & $\mathrm{~N} . \mathrm{D}$ \\
\hline $\mathbf{K}$ & $0.088 \pm 0.003$ & $0.06 \pm 0.01$ & $0.076 \pm 0.003$ \\
\hline $\mathbf{C a}$ & $0.8 \pm 0.1$ & $0.42 \pm 0.04$ & $0.58 \pm 0.03$ \\
\hline $\mathbf{T i}$ & $0.013 \pm 0.003$ & $0.007 \pm 0.002$ & $0.009 \pm 0.001$ \\
\hline $\mathbf{C r}$ & $0.002 \pm 0.001$ & $\mathrm{~N} . \mathrm{D}$ & $0.002 \pm 0.001$ \\
\hline $\mathbf{M n}$ & $0.008 \pm 0.004$ & $0.006 \pm 0.001$ & $0.0225 \pm 0.0002$ \\
\hline $\mathbf{F e}$ & $0.4 \pm 0.1$ & $0.25 \pm 0.02$ & $0.51 \pm 0.03$ \\
\hline $\mathbf{N i}$ & $0.007 \pm 0.001$ & $0.003 \pm 0.002$ & $\mathrm{~N} . \mathrm{D}$ \\
\hline $\mathbf{C u}$ & $0.05 \pm 0.01$ & $4.3 \pm 2.1$ & $10.6 \pm 1.2$ \\
\hline $\mathbf{Z n}$ & $0.018 \pm 0.003$ & $\mathrm{~N} . \mathrm{D}$ & $0.015 \pm 0.004$ \\
\hline $\mathbf{A s}$ & $0.45 \pm 0.02$ & $0.18 \pm 0.04$ & $0.11 \pm 0.02$ \\
\hline $\mathbf{P b}$ & $0.25 \pm 0.03$ & $1.6 \pm 0.1$ & $0.03 \pm 0.01$ \\
\hline $\mathbf{S r}$ & $0.066 \pm 0.004$ & $0.05 \pm 0.01$ & $0.021 \pm 0.002$ \\
\hline
\end{tabular}

N.D: Non-detected
It was also possible to detect additional heavy elements, such as $\mathrm{Ti}$ and $\mathrm{Cr}$. In this case, their normalized net counts values are more or less similar in all the lake pigments, even if in the pink lake pigment $117342 \mathrm{Cr}$ was under the limit of detection. The obtained similar values suggest that they can be original elements present in the inorganic binders used to create these pigments.

Regarding the elements with an atomic number lower than 13, Al, Si and P were also detected. The presence of $\mathrm{Al}$ and $\mathrm{Si}$ could suggest that the inorganic binder used to manufacture this three Pompeian lake pigments could be an aluminosilicate. The ratio of normalized net counts of Si vs. Al is coincident in the two pink lake pigments (ratio $\mathrm{Si}_{\mathrm{Al}}=1.3$ ) and it is higher for the purple lake pigment ( ratio $_{\mathrm{Si} / \mathrm{Al}}=2.9$ ).

In order to confirm a possible heterogeneity in the composition of the lake pigments at a microscopic scale and the presence of light elements, SEM-EDS analyses were conducted. Taking into account that the EDS spectrometer performs elemental analyses at a microscopic scale, selective measurements were conducted on the blue and pink grains of the purple lake pigment. In Figure 3, the average net area of each element obtained from ten repetitive measurements performed on each lake pigment is shown. As it can be observed, additional elements with an atomic number lower or equal than 12 , such as $\mathrm{C}, \mathrm{O}, \mathrm{F}, \mathrm{Na}$, and $\mathrm{Mg}$ can be detected with the EDS. Taking into account that ancient Roman town of Pompeii is located very close to the Bay of Naples and, therefore, near to the sea, the presence of $\mathrm{F}, \mathrm{Na}$ and $\mathrm{Mg}$ could be attributed to the influence of the marine aerosol. ${ }^{23,27-29}$ This sea salt aerosol usually contains $\mathrm{Mg}$ (mainly in the form of sulfates), $\mathrm{Na}$ (predominantly as chlorides) and F. Moreover, $\mathrm{Mg}$ could also be present in the original composition of the inorganic binder used in the manufacture of the lake pigments. The possible presence of these elements in the volcanic material and the soil covering the raw lake pigments bowls cannot be rejected either.

It is also remarkable that with the EDS measurements it was possible to detect the presence of $\mathrm{S}$ in all of the lake pigments, whereas $\mathrm{Cl}$ was only detected in some isolated replicate measurements of the pink lake pigment 117323. That is the reason why we did not include this information in the average values shown in Figure 3. The presence of $\mathrm{S}$ in the pigments could be due to the influence of volcanic material deposition on the raw lake pigments bowls. A lower contribution could also come from the sea salt aerosol. However, neither $\mathrm{S}$ nor $\mathrm{Cl}$ were detected by ED-XRF due to their higher limit of detection with this instrumentation. In addition, it is logical that $\mathrm{Cl}$ was not detected, since the $\mathrm{Rh}$ L-lines coming from the anode of the $\mathrm{X}$-ray tube interfere in the detection of the $\mathrm{Cl} \mathrm{K}$-lines, and the expected chloride concentration in the lake pigments was very low.

On the contrary, EDS technique did not allow the detection of some heavier elements such as $\mathrm{Pb}, \mathrm{Ti}, \mathrm{Cr}, \mathrm{Mn}, \mathrm{Ni}, \mathrm{Zn}$ and $\mathrm{Sr}$ which, in contrast, were easily detected by means of EDXRF measurements. It is especially remarkable that, although $\mathrm{Pb}$ is widely present in the lake pigments, EDS was not able to detect its presence. In previous works reported in the literature, ${ }^{10}$ EDS technique was not able either to detect the presence of heavier elements (including $\mathrm{Pb}$ ) in Pompeian purple lake pigments. 
As far as the purple lake pigment 117365 is concerned, the isolated measurement of the blue crystals revealed a completely different composition showing the presence of $\mathrm{C}, \mathrm{O}, \mathrm{Na}, \mathrm{Al}$, $\mathrm{Si}, \mathrm{Ca}$ and $\mathrm{Cu}$. The areas of $\mathrm{C}, \mathrm{O}$ and $\mathrm{Al} \mathrm{K}$-lines are lower than in the pink lake pigments measurements. On the contrary, the areas of $\mathrm{Si}, \mathrm{Ca}$ and $\mathrm{Cu} \mathrm{K}$-lines are considerably higher in blue grains of 117365 than in the pink lake pigments. This result supports the hypothesis of the use of the Pompeian blue pigment.

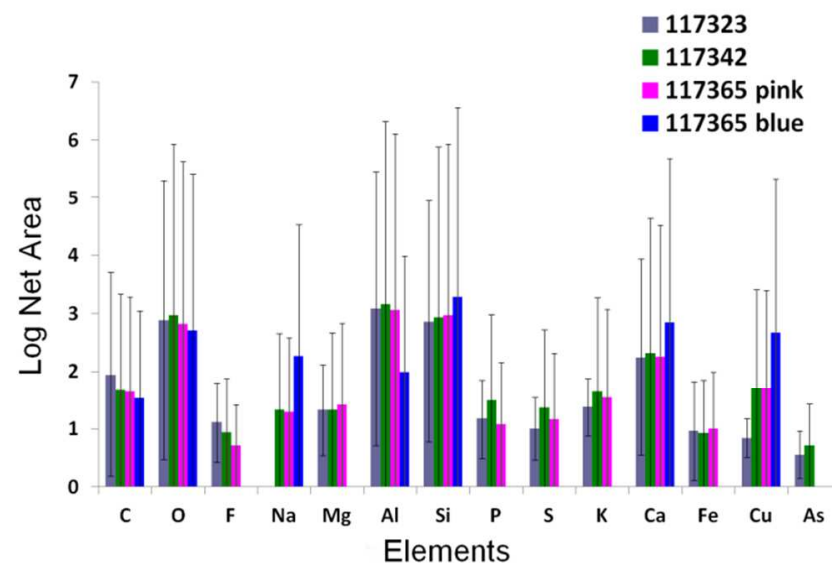

Figure 3. Average of net areas and their relative standard deviations for each element detected on the Pompeian lake pigments by means of EDS.

Major, minor and trace elements quantification and isotopic ratio analysis. ICP-MS analysis of the acid extracts of the samples was done in order to quantify the major, minor and trace elements present in the lake pigments. As can be observed in Table 2, Al, Si and $\mathrm{Ca}$ are the major elements in the inorganic matrix from the lake pigment, as it was observed with the previously used non-invasive techniques. The ICPMS results agree with those obtained with the HH-ED-XRF and ED-XRF measurements in the laboratory, since $\mathrm{K}, \mathrm{Ca}, \mathrm{Fe}$, $\mathrm{Ni}, \mathrm{Zn}$ and As concentrations are higher in the pink lake pigment 117323 than in the 117342 . Moreover, the concentration of Fe quantified by ICP-MS agrees with the tendency observed with ED-XRF (both in-situ and laboratory) and EDS analyses since it is higher in the pink lake pigment 117323 than in the purple lake pigment 117365 . However, the net areas of $\mathrm{K}, \mathrm{Ca}$ and $\mathrm{As} \mathrm{K}$-alpha lines are higher in the pink lake pigment 117342 than in the 117323 . This observation suggests that special care must be taken in order to extract definitive and comparative conclusions using only the spectral information coming from EDS measurements.

The concentration of metals such as $\mathrm{Ba}, \mathrm{Na}, \mathrm{Mg}, \mathrm{Li}, \mathrm{Mo}$, $\mathrm{Ag}, \mathrm{Sn}, \mathrm{Hg}, \mathrm{Ti}, \mathrm{Co}, \mathrm{Cd}, \mathrm{V}$ and $\mathrm{Cr}$ detected by means of ICPMS, which were under the limit of detection of ED-XRF and EDS techniques, is higher in the pink lake pigment 117323 than in the 117342 one. It is also confirmed by all the used techniques that among the pink lake pigments, the sample 117342 presents the highest concentration of $\mathrm{Cu}$ and $\mathrm{Pb}$ (although $\mathrm{Pb}$ was not detect by means of EDS).

Regarding $\mathrm{Cu}$, the pink lake pigment 117342 presents the highest concentration, followed by the purple lake pigment 117365. This seems in contradiction to what it has been observed by means of ED-XRF and EDS analyses. As the blue pigment grains (probably Pompeian blue) of 117365 purple lake pigment were not solubilized using the applied acid ex- traction procedure -since they are mainly composed by a silicate- it must be assumed that in the acid extract, Pompeian blue contribution was little or non-existent. The noticeable concentration of $\mathrm{Cu}$ in the pink lake pigments could be due to an intentionally addition of this element. It is well referenced that since Roman times, copper salts (in form of oxides or sulfates) were added to the inorganic binder from lake pigments to obtain the desired final hue. This variation in the original tonality takes place when the added copper $\left(\mathrm{Cu}^{2+}\right)$ forms a complex with the organic molecules (e.g. alizarin and purpurin when madder root dye is used) from the colorant used to dye the inorganic binder. ${ }^{30,31}$

Table 2. Concentration of major ( $\%$ weight), minor and trace elements $\left(\mu \mathrm{g} \cdot \mathrm{g}^{-1}\right)$ on the inorganic binder of each lake pigment and \% RSD (Relative Standard Deviation) $(n=3)$ obtained by means of ICP-MS.

\begin{tabular}{|c|c|c|c|c|}
\hline \multicolumn{5}{|c|}{ Major elements (\% weight) } \\
\hline Elements & 117323 & 117342 & 117365 & $\%$ RSD \\
\hline Al & 14.0 & 16.9 & 5.6 & 5 \\
\hline $\mathbf{S i}$ & 7.4 & 2.2 & 1.8 & 7 \\
\hline $\mathbf{C a}$ & 39.8 & 2.3 & 6.5 & 17 \\
\hline $\mathbf{N a}$ & 5.0 & 0.4 & 1.2 & 6 \\
\hline \multicolumn{5}{|c|}{ Minor and Trace elements $\left(\mu \mathrm{g} \cdot \mathrm{g}^{-1}\right)$} \\
\hline Elements & 117323 & 117342 & 117365 & \% RSD \\
\hline Mg & 16358 & 9193 & 2038 & 6 \\
\hline $\mathbf{K}$ & 14172 & 5153 & 4000 & 6 \\
\hline $\mathbf{F e}$ & 7970 & 1556 & 2771 & 3 \\
\hline Zn & 2528 & 304 & 854 & 10 \\
\hline As & 1948 & 1411 & 97 & 11 \\
\hline $\mathbf{C u}$ & 1228 & 12937 & 7736 & 18 \\
\hline $\mathbf{P b}$ & 987 & 2083 & 1466 & 2 \\
\hline $\mathrm{Sr}$ & 874 & 357 & 196 & 3 \\
\hline Mn & 401 & 399 & 227 & 6 \\
\hline $\mathbf{V}$ & 369 & 78 & 64 & 5 \\
\hline $\mathbf{B a}$ & 312 & 152 & 54 & 1 \\
\hline $\mathbf{T i}$ & 270 & 76 & 123 & 8 \\
\hline $\mathrm{Cr}$ & 150 & 34 & 42 & 3 \\
\hline $\mathbf{H g}$ & 129 & 52 & 27 & 3 \\
\hline $\mathbf{N i}$ & 112 & 43 & 19 & 4 \\
\hline Sn & 58 & 6 & 42 & 4 \\
\hline $\mathbf{L i}$ & 34 & 4 & 5 & 1 \\
\hline Co & 13 & 12 & 4 & 5 \\
\hline $\mathbf{W}$ & 10 & 8 & 3 & 4 \\
\hline Ag & 9 & 2 & 3 & 1 \\
\hline Cd & 8 & 1 & 1 & 10 \\
\hline Sb & 3 & 37 & 3 & 2 \\
\hline Tl & 0.05 & 0.1 & 0.04 & 10 \\
\hline
\end{tabular}

It is necessary to remark the unexpected high concentration of $\mathrm{Pb}$ in the three lake pigments, especially in the pink lake pigment 117342 and in the purple lake pigment 117365 . Concentration values close to or higher than $1000 \mu \mathrm{g} \cdot \mathrm{g}^{-1}$ cannot be attributed to a natural background of a clay or soil, which are the most plausible components used as inorganic binder in these lake pigments. Additionally, as it is going to be described in the section related with molecular analyses, it was not possible to detect any compound related with lead in the lake pigments (e.g. lead white or $\left.\left(\mathrm{PbCO}_{3}\right)_{2} \cdot \mathrm{Pb}(\mathrm{OH})_{2}\right)$. Thus, it could be assumed that the $\mathrm{Pb}$ present in these lake pigments could have an anthropogenic origin. 
To confirm this hypothesis, a $\mathrm{Pb}$ isotopic ratio analysis was conducted. Among all of the naturally occurring lead isotopes only ${ }^{204} \mathrm{~Pb}$ is non-radiogenic, whereas ${ }^{206} \mathrm{~Pb},{ }^{207} \mathrm{~Pb}$ and ${ }^{208} \mathrm{~Pb}$ are daughter products from the radioactive decay of ${ }^{238} \mathrm{U},{ }^{235} \mathrm{U}$ and ${ }^{232} \mathrm{Th}$, respectively. This fact produces small $\mathrm{Pb}$ isotope abundance variations in nature. Furthermore, it is well known that the isotopic composition of $\mathrm{Pb}$ in natural materials is clearly dependent on the ore deposits from which it comes, thus lead isotopic ratio can provide analytical information about sources of lead contamination. ${ }^{32}$ As far as we know, the ${ }^{206} \mathrm{~Pb} /{ }^{207} \mathrm{~Pb}$ isotopic ratio for the volcanic materials is around 1.21-1.22. ${ }^{33}$ Moreover, in a previous work, the characterization of in-depth soil from the Campania region, where the ancient city of Pompeii is located, set a ${ }^{206} \mathrm{~Pb} /{ }^{207} \mathrm{~Pb}$ isotopic ratio around $1.21 .^{34}$ The ${ }^{206} \mathrm{~Pb} /{ }^{207} \mathrm{~Pb}$ isotopic ratio determined in the pink lake pigment 117323 and purple lake pigment 117365 was 1.183 and the one for the pink lake pigment 117342 was 1.193 . The lower isotopic ratios obtained could suggest an anthropogenic source of lead in these lake pigments. ${ }^{34}$

Lead pipes were commonly employed in the ancient city of Pompeii. According to the literature, the use of these kinds of pipes promoted the possible poisoning of the drinking water from Pompeii. ${ }^{32}$ In recent excavations, these kinds of pipes came to light. It is also well referenced that the archaeological soil from ancient Roman cities was rich in $\mathrm{Pb}$, reaching concentrations of $1000 \mu \mathrm{g} \cdot \mathrm{g}^{-1}$. ${ }^{35}$ Probably this high concentration could be explained due to the leaching process from the lead pipes of the ancient Roman cities water system. It is also reported, that the ${ }^{206} \mathrm{~Pb} /{ }^{207} \mathrm{~Pb}$ isotopic ratio of the lead pipes from Pompeii is $1.18 .^{36}$ This value is very close to those determined for the Pompeian lake pigments under study. Therefore, it could be suggested that the possible aluminosilicate clay used as inorganic binder have a notable concentration of $\mathrm{Pb}$ due to the $\mathrm{Pb}$ leaching from the surrounding lead pipes.

Molecular analysis of the lake pigments in the laboratory. To determine the molecular composition of the inorganic matrix of the Pompeian pink and purple lake pigments, microRaman measurements were performed directly on all the samples. The first attempt at studying the lake pigments failed because of the strong fluorescence that occurred during the acquisition, especially when analyzing the pink lake pigments with the $785 \mathrm{~nm}$ laser (see Figure S-2). In order to determine the mineralogical composition of the blue crystals present in the purple lake pigment 117365 direct Raman measurements were performed on isolated blue crystals. Due to the high fluorescence provided by the inorganic binder, the Raman spectra were acquired in two spectral ranges. The best spectral results were acquired using the $532 \mathrm{~nm}$ excitation laser, obtaining Raman bands related with Pompeian blue at 357, 431, 462, 571, 967, 990, 1012 and $1085 \mathrm{~cm}^{-1}$ (see Figure S-3). Therefore, Raman results were consistent with the previously obtained elemental results.

In order to go deeper in the molecular characterization of the inorganic binder, XRD analyses were also performed. The obtained diffractograms for some of the lake pigments under study showed the typical pattern of an amorphous matrix (see Figure S-3). In the pink lake pigment 117323, possible traces of kaolinite $\left(\mathrm{Al}_{2} \mathrm{Si}_{2} \mathrm{O}_{5}(\mathrm{OH})_{4}\right)$ were observed. For the purple lake pigment 117365 , apart from quartz, the presence of Pompeian blue was also determined (see Figure S-4) agreeing with the Raman and elemental results.
To complete the molecular characterization of the inorganic matrix of the lake pigments under study, additional infrared analyses were performed in ATR mode. Figure 4A shows a representative and repetitive infrared spectrum obtained in all the lake pigments. The infrared bands of the spectrum from the pink lake pigments can be related with poorly crystalline aluminosilicate clays. This kind of mineral matrix usually provides a high fluorescence in Raman spectroscopy being its identification quite difficult, if not impossible as already mentioned at the beginning of this section. The broad band around $3360 \mathrm{~cm}^{-1}$ can be assigned to the stretching vibrations of hydroxyl groups and adsorbed $\mathrm{H}_{2} \mathrm{O}$. The bands of medium intensity $\left(1633,1576\right.$, and $\left.1427 \mathrm{~cm}^{-1}\right)$ can be related to the $\mathrm{H}-\mathrm{O}-\mathrm{H}$ deformation vibrations of adsorbed $\mathrm{H}_{2} \mathrm{O}$. Particularly, the band centered at $1633 \mathrm{~cm}^{-1}$ could be associated with $\mathrm{O}-\mathrm{H}$ deformation vibration of water in silicate clays. ${ }^{37}$ The strong band at $998 \mathrm{~cm}^{-1}$ can be related with the Si-O-Si stretching vibrations. Considering that with the ATR measurements information can be lost in the $750-400 \mathrm{~cm}^{-1}$ spectral range, additional analyses in FTIR mode of the lake pigments prepared as pellets were conducted (see Figure 4B). The FTIR spectrum obtained for both pink lake pigments is very similar to the one obtained using the ATR mode, although in the FTIR spectrum additional infrared bands at 575 and $448 \mathrm{~cm}^{-1}$ can be observed. These bands are also related with amorphous to poorly crystalline aluminosilicate clay mineraloids. Actually, the detected bands between $4000-750 \mathrm{~cm}^{-1}$ and the two additional bands at lower wavenumber can be related with allophane $\left(\mathrm{Al}_{2} \mathrm{O}_{3} \cdot\left(\mathrm{SiO}_{2}\right)_{1.3-}\right.$ $\left.{ }_{2} \cdot(2.5-3) \mathrm{H}_{2} \mathrm{O}\right)$ or imogolite $\left(\mathrm{Al}_{2} \mathrm{SiO}_{3}(\mathrm{OH})_{4}\right){ }^{38}$ Both clays can occur in soils formed from volcanic ash and they can be rapidly originated by weathering or hydrothermal alteration of volcanic materials under neutral to slightly acidic conditions. Taking into account that the Pompeian soil has volcanic origin, geological deposits of allophane and/or imogolite would have been potentially available to painters in this region, so that we must consider the hypothesis of a local origin for the inorganic binder used to elaborate the lake pigments.

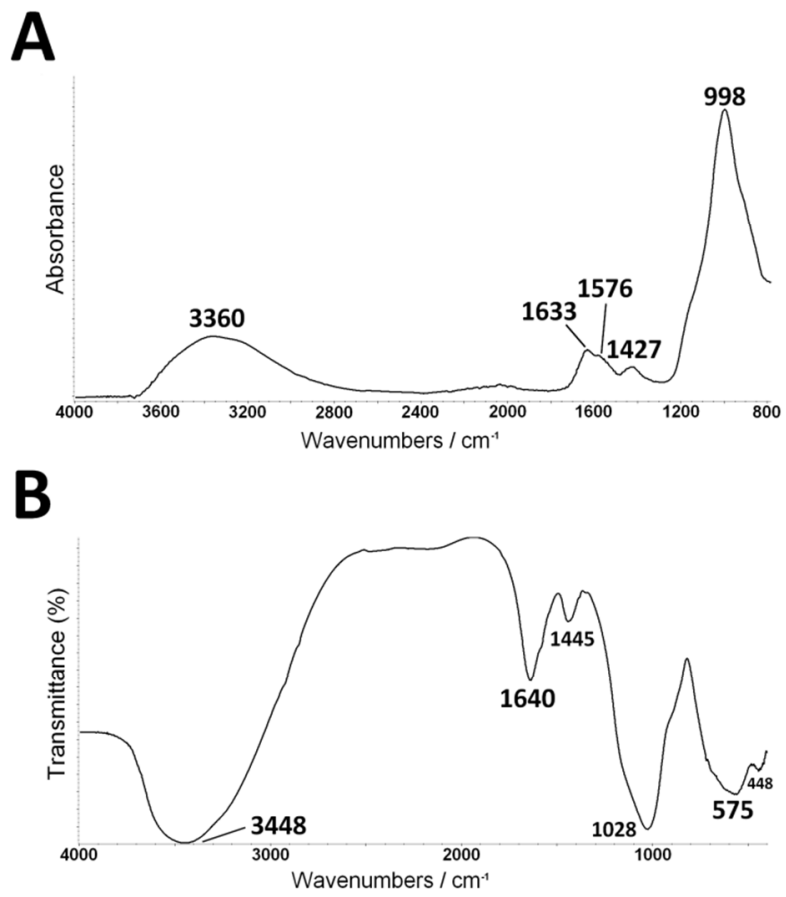


Figure 4. (A) Representative and repetitive ATR spectrum of the pink lake pigments under study and (B) Representative and repetitive FTIR spectrum of the pink lake pigments under study.

The infrared bands at $575 \mathrm{~cm}^{-1}$ and $1028 \mathrm{~cm}^{-1}$ in the FTIR spectrum $\left(998 \mathrm{~cm}^{-1}\right.$ in ATR spectrum) can be used as markers to distinguish among these two mineral phases. Imogolite generally has sharper bands than those from allophane, and it also has characteristic doublets of the bands around 1000 and $575 \mathrm{~cm}^{-1} .{ }^{39}$ All the infrared spectra acquired in both pink lake pigments have broad bands without splitting, therefore, it can be pointed out that the main amorphous to poorly crystalline aluminosilicate clay is the allophane.

The obtained FTIR spectrum for the Pompeian purple lake pigment was slightly different, especially in the spectral region of $1000-400 \mathrm{~cm}^{-1}$ (see Figure S-5). The results confirm the presence of Pompeian blue, already identified by microRaman spectroscopy and XRD carried out in the blue colored grains contained within the purple lake pigment. Apart from Pompeian blue, in the FTIR spectrum of the purple lake pigment (see Figure S-5), infrared bands related with clays were also present (e.g. 1011, 754 and $661 \mathrm{~cm}^{-1}$ ). In this case it was not possible to identify the presence of the infrared band at $575 \mathrm{~cm}^{-1}$, thus it was not possible to determine exactly the composition of the clay used as inorganic binder. Instead, infrared bands related with deformation vibrations of Al-O-Si bonds were identified (754 and $661 \mathrm{~cm}^{-1}$, among others) which only allowed to confirm that the inorganic fraction composing the lake pigment is indeed an aluminosilicate clay.

\section{CONCLUSIONS}

In this work a multi-analytical approach mainly based on the use of non-invasive spectroscopic techniques, but also on the additional use of a destructive technique (ICP-MS), has been successfully applied to characterize the mordant used to manufacture two Pompeian pink (117323 and 117342) and one purple (117365) lake pigments recovered from the excavation of the archaeological site of Pompeii and preserved in the Naples National Archaeological Museum (Italy).

The combination of elemental and molecular spectroscopic techniques has proved to be crucial for the proper characterization of the inorganic materials used to elaborate these lake pigments. We demonstrated that the results obtained from the handheld ED-XRF spectrometer are comparable to those obtained from the benchtop ED-XRF configuration. This issue could be of great importance when the possibility of extracting micro-samples of archaeological remains is not allowed.

SEM-EDS proved to be very useful for the determination of elements with an atomic number lower or equal than 12 such as $\mathrm{F}, \mathrm{Na}$, and $\mathrm{Mg}$, although it failed on the detection of heavier elements such as $\mathrm{Pb}$. In this sense, the supplementary use of ED-XRF and ICP-MS elemental techniques, which offer a lower limit of detection for heavier elements, was very helpful.

The employment of the $785 \mathrm{~nm}$ laser for the micro-Raman analyses proved to be completely useless when analyzing both types of pigment due to the high fluorescence that overlapped with the bands of any mineral present in the samples. Luckily, thanks to the use of the $532 \mathrm{~nm}$ laser, we were able to distin- guish some Raman bands related with Pompeian blue in blue colored grains composing the purple lake pigment.

XRD and infrared spectroscopy in ATR mode were very helpful to characterize the mineralogical phase composing the inorganic binder, although it is worth mentioning that the additional analyses in FTIR mode allowed not only to identify the presence of allophane but also to confirm the presence of Pompeian blue in the purple lake pigment.

Regarding the chemical-mineralogical characterization of the inorganic binder used to manufacture the Pompeian pink and purple lake pigments, determined that an amorphous to poorly crystalline aluminosilicate clay mineraloid was employed.

The presence of F, Na, and $\mathrm{Mg}$ could be attributed to the influence of the marine aerosol, although it could also originated from the inorganic binder used on the elaboration of the lake pigments, or be part of the sediments covering the raw lake pigments bowls.

It is noteworthy to highlight the unexpected significant presence of $\mathrm{Pb}$ in the three lake pigments. The concentration of this element, clearly exceeding the proportions of the trace level, is likely to be related with an anthropogenic origin rather than to a natural origin. After the isotopic ratio analysis of this element, we suggest that the presence of this metal may be due to the leaching of the Pompeian ancient lead pipes and a subsequent $\mathrm{Pb}$ enrichment of the clays used to create the lake pigments. This hypothesis is supported by the fact that some amorphous to poorly crystalline aluminosilicates from volcanic soils have a great capacity to absorb metals such as $\mathrm{Cu}, \mathrm{Zn}$, $\mathrm{Ni}, \mathrm{Cd}$ and $\mathrm{Pb}^{40}$ In this sense, taking into account that the bowls containing the three lake pigments under study were buried during more or less 2000 years, the continuous leaching of $\mathrm{Pb}$ to the surrounding soils could also contribute to increase this metal concentration in the pigments. The same could happen for the case of $\mathrm{Cu}$; apart from an intentionally addition of copper salts by manufacturers, this kind of clay used as inorganic binder could absorb it from the soil (apart from $\mathrm{Pb}$ ), explaining in this way its higher concentrations found in the pigments.

\section{ASSOCIATED CONTENT}

\section{Supporting Information}

The Supporting Information is available free of charge on the ACS Publications website. Figures S- 1 to S-5 and Table S- 1 to S-3.

\section{AUTHOR INFORMATION}

\section{Corresponding Author}

E-mail: maite.maguregui@ehu.eus, phone: +34 946018299

\section{Author Contributions}

The manuscript was written through contributions of all authors. All authors have given approval to the final version of the manuscript.

\section{ACKNOWLEDGMENT}


The authors would like to thank the Naples National Archaeological Museum for the permissions given to perform the insitu measurements of the raw lake pigments contained in the original bowls and deposited in this museum and also for the permissions given to extract samples from these pigment bowls. This work has been funded by the Ministry of Economy and Competitiveness (MINECO) and the European Regional Development Fund (FEDER) through the project DISILICA-1930 (ref. BIA2014-59124-P). Iker Marcaida is grateful to the Basque Government who funded his predoctoral fellowship. Technical support provided by the General Xray Service of the SGIKer (UPV/EHU, MICINN, GV/EJ, ERDF and ESF) for the X Ray Diffraction analyses and also by Raman-LASPEA laboratory of the SGIker (UPV/EHU, MICINN, GV/EJ, ERDF and ESF) is also gratefully acknowledged.

\section{REFERENCES}

(1) Sandalinas, C., Ruiz-Moreno, S., López-Gil, A., \& Miralles, J. J. Raman Spectrosc. 2006, 37, 1146-1153.

(2) d'Errico, F., Backwell, L., Villa, P., Degano, I., Lucejko, J. J., Bamford, M. K., Higham, T., Colombini, M.P. \& Beaumont, P. B. Proc. Natl. Acad. Sci. 2012, 109, 13214-13219.

(3) Forbes, R. J. Studies in ancient technology. 4. Brill Archive. 1964.

(4) Gaius Plinius Secundus. Naturalis Historia. AD 77, 35, 44.

(5) Bruni, S., Guglielmi, V., \& Pozzi, F. J.Raman Spectrosc. 2010, 41, 175-180.

(6) Aceto, M., Idone, A., Agostino, A., Fenoglio, G., Gulmini, M., Baraldi, P., \& Crivello. Spectrochim. Acta A. 2014, 117, 34-41.

(7) Clarke, M., Frederickx, P., Colombini, M.P., Andreotti, A., Wouters, J., van Bommel, M., Eastaugh, N., Walsh, V., Chaplin, T. and Siddall, R. Proceedings of Art'05 8th International Conference on "Non Destructive Investigations and Microanalysis for the Diagnostics and Conservation of the Cultural and Environmental Heritage”, Lecce, Italy, May $15^{\text {th }}-19^{\text {th }} 2005$.

(8) Aliatis, I., Bersani, D., Campani, E., Casoli, A., Lottici, P. P., Mantovan, S., Marino, I.G. \& Ospitali, F. Spectrochim. Acta A. 2009, 73, 532-538.

(9) Giachi, G., De Carolis, E., \& Pallecchi, P. Mater. Manuf. Process. 2009, 24, 1015-1022.

(10) Aliatis, I., Bersani, D., Campani, E., Casoli, A., Lottici, P. P., Mantovan, S., \& Marino, I. G. J. Raman Spectrosc. 2010, 41, 1537-1542.

(11) Duran, A., Jimenez De Haro, M. C., Perez-Rodriguez, J. L., Franquelo, M. L., Herrera, L. K., \& Justo, A. Archaeometry. 2010, 52, 286-307.

(12) Augusti, S. I colori Pompeiani, Ministero della Pubblica Istruzione, Direzione Generale delle Antichità e Belle Arti: Rome, 1967.

(13) Siddall, R. InFocus Magazine: Proceedings of the Royal Microscopical Society. 2006, 2, 18-23.

(14) Madariaga, J. M., Maguregui, M., Fernández-Ortiz, S., Knuutinen, U., Castro, K., Martinez-Arkarazo, I., Giakoumaki, A., \& Pitarch, A. J. Raman Spectrosc. 2014, $45,1059-1067$.
(15) Maguregui, M., Knuutinen, U., Martínez-Arkarazo, I., Giakoumaki, A., Castro, K., \& Madariaga, J. M. J.Raman Spectrosc. 2012, 43, 1747-1753.

(16) Oujja, M., Sanz, M., Agua, F., Conde, J. F., GarcíaHeras, M., Dávila, A., Oñate, P., Sanguino J., Vazquez de Aldana, J.R., Moreno, P., Villegas, M. A. \& Castillejo, M. J. Anal. Atom. Spectrom. 2015, 30(7), 15901599.

(17) Aceto, M., Agostino, A., Fenoglio, G., Gulmini, M., Bianco, V., \& Pellizzi, E. Spectrochim. Acta A. 2012, 91, 352-359.

(18) Romani, A., Clementi, C., Miliani, C., \& Favaro, G. Accounts of Chem. Research 2010, 43, 837-846.

(19) Pitarch, A., Ruiz J.F., Fdez-Ortiz de Vallejuelo, S., Hernanz, A., Maguregui, M., Madariaga, J.M. Anal. Mehods. 2014, 6, 6641-6650.

(20) Madariaga, J.M., Maguregui, M., Castro, K., Knuutinen, U., Martínez-Arkarazo, I. Appl. Spectrosc. 2016, 70, 137-146.

(21) Morillas, H., Maguregui, M., García-Florentino, C., Carrero, J.A., Salcedo, I., Madariaga, J.M. Environ. Res. 2016, 147, 218-232

(22) Inductively coupled plasma spectrometry and its applications. 2008, Ed. Steve J. Hill. Pag 172-177

(23) Morillas, H., Maguregui, M., Paris, C., Bellot-Gurlet, L., Colomban, P., \& Madariaga, J. M. Microchem. J. 2015, 123, 148-157.

(24) Maguregui, M., Prieto-Taboada, N., Trebolazabala, J., Goienaga, N., Arrieta, N., Aramendia,J., Gomez-Nubla, L., Sarmiento, A., Olivares, M., Carrero, J.A., Martinez-Arkarazo, I., Castro, K., Arana, G., Olazabal, M.A., Fernandez, L.A., Madariaga, J.M., CHEMCH 1st International Congress Chemistry for Cultural Heritage, Ravenna, 30th June-3rd July 2010.

(25) Castro, K., Pérez-Alonso, M.,. Rodríguez-Laso, M. D., Fernández, L. A., \& Madariaga J. M., Anal. Bioanal. Chem. 2005, 382, 248.

(26) Downs, R. T. The RRUFF Project: an integrated study of the chemistry, crystallography, Raman and infrared spectroscopy of minerals. In Program and abstracts of the 19th general meeting of the international mineralogical association in Kobe, Japan (Vol. 3). 2006

(27) Morillas, H., Maguregui, M., Gómez-Laserna, O., Trebolazabala, J., \& Madariaga, J.M. J. Raman Spectrosc. 2012, 43, 1630-1636.

(28) Morillas, H., Maguregui, M., Gómez-Laserna, O., Trebolazabala, J., \& Madariaga, J.M. J. Raman Spectrosc. 2013, 44, 1700-1710.

(29) Morillas, H., Maguregui, M., García-Florentino, C., Marcaida, I., \& Madariaga, J. M. Sci. Total Environ. 2016, 550, 285-296.

(30) Davy, H. Phil. Trans.R. Soc. Lon, 1815, 105, 97-124.

(31) Bechtold, T., \& Mussak, R. Handbook of natural colorants. John Wiley \& Sons: Chichester 2009.

(32) Ruiz Encinar, J., García Alonso, J.I., Sanz-Medel, A., Main, S., Turner, P.J. J. Anal. At. Spectrom. 2001, 16, 315-321.

(33) Fulignati, P., Kamenetsky, V. S., Marianelli, P., Sbrana, A., \& Meffre, S. J. Volcanol. Geoth. Res. 2011, 200, 223-233.

(34) Bove, M. A., Ayuso, R. A., De Vivo, B., Lima, A., \& Albanese, S. J. Geochem. Explor. 2011, 109, 38-50. 
(35) Morris M.W., Foss J.E., Timpson M.E., Lee S.Y., Stiles C.A. "Using Archaeological Sites to Evaluate Human Impact on Soil Systems" Scientific registration $\mathrm{n}^{\circ}: 367$ Symposium $\mathrm{n}^{\circ}: 45$ Presentation : Poster.

(36) Boni, M., \& DI, G. Archaeometry 2000, 42, 201-208.

(37) Kitagawa, Y. J. Soil Sci. Plant Nutr.1974, 20, 195-196.

(38) Parfitt, R. L., \& Henmi, T. J. Soil Sci. Plant Nutr. 1982, 28, 183-190.

(39) Gustafsson, J. P., Karltun, E., \& Bhattacharya, P. Allophane and imogolite in Swedish soils. Division of Land and Water Resources, Department of Civil and Environmental Engineering. Royal Institute of Technology (KTH), Stockholm, 1998.

(40) Parelho, C., Rodrigues, A. S., Cruz, J. V., \& Garcia. Sci. Total Environ. 2014, 496, 241-247.

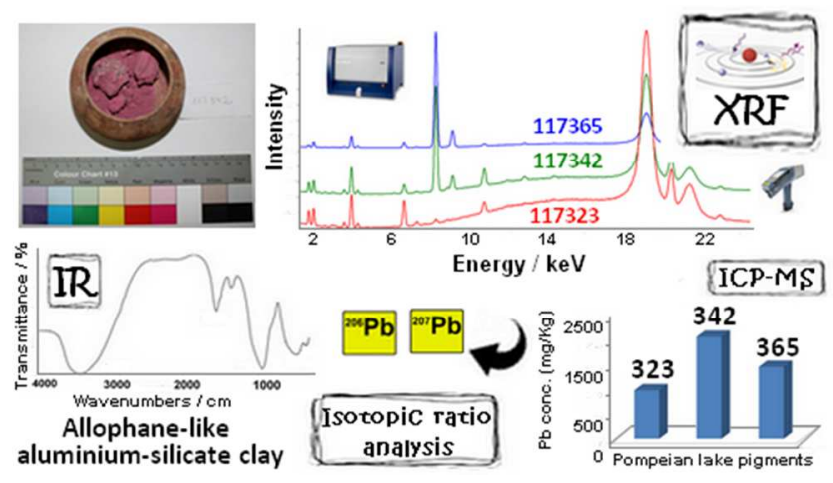

